\title{
Erratum
}

\section{Supercritical Markov Branching Processes with General Set of Types}

\author{
H. Hering
}

Z. Wahrscheinlichkeitstheorie verw. Gebiete 26, 1-16 (1973)

Page 4, (2.1): Read " $(\alpha / \rho)^{t / 2}$ " instead of " $(\alpha / \rho)^{-t / 2 "}$.

Page 6, fourth line from the bottom: Read " $\ldots 0 \leqq \alpha / \rho<1<\rho, \ldots$ ".

Page 7, line 10: Read “ $(\alpha / \rho)^{\varepsilon / 2}$ " instead of " $(\alpha / \rho)^{-\varepsilon / 2 "}$.

Page 12, (4.9): Read " 1 " instead of " $\infty$ ".

Page 13 , line 6: Read “.. strongly differentiable in $s \in\{|s| \geqq b\}$.

H. Hering

D-1 Berlin 37

Beuckestr. 26 